\title{
An Overview on The Pandemic Coronavirus Disease 2019 (COVID- 19) Outbreak
}

\author{
Mariwan Abdulla Hama Salih \\ Medical Laboratory Department \\ Technical College of Health \\ Sulaimani Polytechnic University \\ Sulaimani- Iraq \\ mariwan.abdulla@spu.edu.iq
}

\begin{tabular}{l} 
Article Info \\
\hline Special Issue on \\
Coronavirus (COVID-19) \\
DOI: \\
10.24017/covid.4 \\
Article history: \\
Received : 01 May 2020 \\
Accepted : 03 May 2020 \\
\hline
\end{tabular}

Keywords:

COVID-19,

SARS-COV-2,

Coronavirus Diseases 2019,

2019-nCoV,

Coronavirus,

SPU.

\section{ABSTRACT}

The current review covered most of the researches have been done since the new coronavirus found in Wuhan city of China at the end of December 2019 up to date by considering the most beneficial ones for our society. The severe acute respiratory syndrome coronavirus 2 or SARS-CoV-2 is a virus that potentially acts on the human respiratory system. It is first found in animal then transmitted into human. The virus can be transmitted between human to human via close contact or from the tiny droplet while coughing or sneezing. WHO characterized the situation by pandemic global concern because the virus spread over 200 territories and more than millions peoples were infected and over two hundred thousand people deceased as a result of COVID-19. At the moment nothing can stop the virus from spreading, neither vaccine nor medicines were found to stop the virus and secure life of people of the planet. The aim of the present review was to show the main feature of the SARSCoV-2 and to find the common statements between the previously published studies on the output of their works. The other objective of this review was to encourage publics to treat the virus in safe way based on the discovery by researchers toward secure life of million peoples that could be infected by the 2019 new coronavirus. This review were summarized several researches about the SARS-CoV-2 since its appearance to present time May 2020. Several reports from WHO, CDC and FDA were included about spreading or the way of transmission, causes, prevention, diagnosis and risk factors of the COVID-19. The current review find the common statements about different aspects of the 2019 new coronavirus that could be help the new research to benefit from these statement for further investigations. This review showed that urgent steps for the current time to secure life of millions peoples is to quarantines people at home and governmental authorities have to take the responsibilities of this steps and to encourage people to stay at home and teach them the self-prevention is a better treatment for all humanities. 


\section{INTRODUCTION}

Novel human coronavirus SARS-CoV-2 is an odd strand and positive sense RNA related to SARS and MERS. It was first found in Wuhan city of China in the late of December 2019. This 2019-nCoV can causes human severe respiratory tract infections and produce further consequences such as lungs impairment, etc. Similar to SARS-CoV and MERS-CoV which are zoonotic in origin i.e. they transmitted from bat and camel respectively, the $2019-\mathrm{nCoV}$ is believed that was first transmitted from animal to human especially from a certain types of Bat that present in China and other territories like Middle East and Europe. There have been concerns about the origin of the animal because other study believed that it can be originated from scaly Pangolin which is also common in china.[1,2] The new infectious diseases was named by WHO with "COVID-19" Coronavirus Diseases 2019.[3] A novel coronavirus SARS-CoV-2 was announced by World Health Organization as pandemic (controllable pandemic) which means that the $2019 \mathrm{nCoV}$ is a global emergency concern, this is after the virus was spread in above a hundred territories.[4] There are several types of human coronavirus found since the first identified at 1960s. According to CDC four of them are known the most commons such as (Alpha CoV 229E and NL63 and Beta CoV OC43 and HKU1). The other two types of coronavirus were known, they are epidemic SARS first identified in china in 2003 and epidemic MERS in Saudia Arabia in 2012.[5] The last one is the pandemic $2019 \mathrm{nCoV}$. The symptom of infection by 2019-nCoV have several common features with other types coronavirus, such as fever, weakness, coughing and sneezing. The difference between 2019-nCoV and other coronaviruses are the severity of infection and the rate of transmission. The 2019-nCoV produces very severe lung infections which lead to impairment of other human organs, and the transmission rate was proved as very fast. In comorbid patients with 2019-nCoV made the situation worsen in comparison with other coronaviruses. Chines researchers claimed that both clinical condition comorbidity and elderly were the risk factors 2019 new coronavirus patients that cause to raise the rate of mortality. [6] The SARS-CoV-2 can be transmitted via close contact with sick people, this statement evidenced by a report in china in January 2020.[7] The objectives of the current review was to collect most of the recent researches and the hypothesis about the virus itself and the way of transmission, in addition to the recent idea to find a vaccination or new medicines to treat the viral infection due to the new coronavirus SARS-CoV-2. The review also aimed to help researchers to use this review as an easily access document of the previous researches that recently have been performed about coronavirus for further involvement in their researches. The other objective of this review was to encourage publics to treat the virus in safe way based on the discovery by researchers toward secure life of millions peoples that could be affected by this virus.

\section{METHODS AND MATERIALS}

To write this review, more than a hundred reports about the SARS-CoV-2 were collected from numbers of publishers were releasing up to date studies. Several researches about the SARSCoV-2 since its appearance to present time May 2020 were summarized. Several other publishers were considered such as Web science, BMJ, and Science Direct as they provide temporary free access for researchers for further investigation to help reducing the risks the 
virus outbreak. Some of the reports from WHO (World Health Organisation), CDC (Center for Disease Control and Prevention), FDA (U.S. Food and Drug Administration) were included about spreading or the way of transmission, causes, prevention, diagnosis and risk factors of the COVID-19. This review also benefited from the news released from trusted web pages of different agencies, such as c\&en (Chemical and Engineering News), and Medicine Net.[8]

\section{RESULTS}

\subsection{Transmission of SARS-CoV-2}

The virus can transmitted through direct contact from human to human[9] or with presymptomatic cases[7], these are reported firstly in china in January 2020, when a family of two members were infected with COVID19 while contacted with presymptomatic traveler during traveling.[7] other cases were reported again in china, the study were included 425 patients were majority $55 \%$ of them were linked human to human transmission. [9] Indirect contact can also result in transportation of the virus, research was conducted in china found that the virus was transmitted in certain mall in china were the infected woman visit the mall and several cases were reported in this place.[10] The aggregation in community also can be an easy way to transmit the virus in very fast way, such as happened in Erbil/ KRG of Iraq, the infected woman was visit traditional condolences event and she was transmitted the virus into more than 100 other peoples most of them women.[11] In china study was performed to analyze the risk of the virus transmission through transportation from infected area to uncontaminated area based on assumption theory based on 19 cases reported outside china, researchers were believed that the virus could transport in to 369 other cities in china if the city of Wuhan was not quarantined.[12] Surfaces are considered other main sources for virus transmission. The persistent of coronavirus out of human body is people concern, research for this purpose ongoing and some study found that the virus can live on the surfaces for about nine days depending on the types of the surfaces and temperature (types of the surface not specified).[13] Another study showed that the virus can live on the contaminated surface made of plastic and stainless steel for up to three days, the study also determined the half-life of the virus by thirteen to sixteen hours on steel and polypropylene respectively.[14] However no research published yet on air transmitted of the virus, [15] but in aerosol droplet the 2019 nCoV can live for about three hours.[13]

\subsection{COVID-19 Sign and Symptom}

Most of the reports that were published restated that the infected patients with SARS-CoV-2 had symptoms ranging from mild to severe. They could appear since infected with the virus in 2-14 days. acute fever, cough, head ache, weakness and flu, Chills, breath difficulties, loss of taste and smell.[16] Otherwise, some patient that infected by the virus COVID-19 were lack of symptoms[7]. For children and elderly the symptoms might be similar to some extent but could be mild and severe respectively.[16]

\subsection{Diagnosis of COVID-19}

The process of diagnosis of the COVID-19 patients is very important steps for following prognosis or monitoring and help to make the treatment process easily achievable. There have been two types tests reported to COVID-19, viral testing and antibody tests (Serology test)[17]. Viral testing is simple and the result will be available in an hour by taking sample of nasopharyngeal swap from the patients. The last one based on the present of antibody in the blood of previous infection of the patient that has to be fighting the virus. The antibody test cannot be used alone for confirming the case.[18] Another method for the patient who carries the 2019 new coronavirus can be used is reverse transcription real time RT-PCR which is specifically used for critical cases because of low sensitivity especially for those patient that has low level of virus at later steps of recovery.[17] The fastest test (IgM/IgG antibody test) for 2019-nCoV is currently available for use, this is after recommendation from USFDA on 16 
March 2020.[19] Chest CT for about thousand COVID-19 patients used, the researcher from published their research by concluding that $\mathrm{CtT}$ can be used as a primary screening tool as a complementary for diagnosis of COVID-19.[20]

\subsection{COVID-19 Risk Factors}

A number of clinical conditions were investigated to produce critical condition for those people when infected with SARS-CoV-2. The mater of age and clinical condition were have been evidenced to increase the mortality rate when human infected with SARS-CoV-2. This is proved by several researches.[6] The retrospective case study was performed on 113 dead patients. The patients who had advanced age with the complication in blood pressure (comorbid patients) were deceased, (68 year median age deceased against 51 years median age recovered) and (68 comorbid patient deceased against 45 recovered).[6] Researcher from the university of California reported that smoking could double the probability of worsen COVID19 , this is evidenced by 12 paper that showed proved worsen progresses of the COVID-19. [21] Another COVID-19 risk factor was reported by American research groups, they showed that obese patients whose age less than 60 years old could be admitted to hospital due to their critical conditions.[22] Another research study indicated that cancer patients with COVID-19 were at higher risk of the COVID-19 than patient without cancer.[23]

\subsection{Vaccines and drugs treatment for COVID-19}

Majority of the people who infected with the new coronavirus 2019 not needed treatments, they directly recovered after a while.[24] Currently there is no drug treatment approved by FDA for the situation. Antiviral drugs remdesivir have been tested by scientist from NIH (National Institute of Health), they found that it can prevent the situation from progression in Monkey.[25] Chloroquine and hydroxyl chloroquine in combination with Azithromycin have been tested on thirty six COVID-19 patients, the result showed hydroxyl chloroquine were significantly stop or reduce the virus load in COVID-19 patients.[26] The recommendation guideline were produced based on the strength and quality rating of the treatment which related to scientific evidence and expert recommendation Table 1.[27] A total of 83 potential COVID-19 vaccines were available up to date (29 April), Despite of WHO restated that vaccination cannot be reliable to save humanity, but researches ongoing to find a promising vaccine for this new coronavirus.[28] The first trial of using convalescent plasma from recovered COVID-19 patients to ten patients with COVID-19 showed promising results, as the viral load disappeared in 7 days with further progressing parameters in the patients.[29]

Table 1: Recommendation rating[27]

\begin{tabular}{lllll}
\hline \multicolumn{3}{c}{ Strength of recommendation } & \multicolumn{2}{c}{ Quality of evidence for recommendation } \\
\hline $\begin{array}{l}\text { A: Strong recommendation for the } \\
\text { statement }\end{array}$ & $\begin{array}{l}\text { I: One or more randomized trials with clinical } \\
\text { outcomes and/or validated end points }\end{array}$ \\
\hline $\begin{array}{l}\text { B: Moderate recommendation for the } \\
\text { statement }\end{array}$ & $\begin{array}{l}\text { II: One or more well-designed non- } \\
\text { randomized trials or observational cohort } \\
\text { studies }\end{array}$ \\
\hline $\begin{array}{l}\text { C: Optional } \\
\text { statement }\end{array}$ & recommendation for the & III: Expert opinion \\
\hline
\end{tabular}

\subsection{Recurred COVID-19}

Despite COVID-19 patients recovery in about 28 day from first confirmed, that because of antibodies present in infected patient blood to fight the virus, but this does not help to protect the recovered patient not to recur the virus again.[30] 


\section{DISCUSSION}

Everyone are at risk to get infected by coronavirus, because the way of transmission and the virus itself have neither eyes nor foot to tell who you are, people from different ages, societies, cultures, ethnics, territories and colors have been reported that they infected by the virus. The sign and symptoms were clearly specified and researchers were agreed on the sign and symptoms of the new coronavirus 2019. The ways of transmission at the begging of the situation was researchers concern, but with fast spreading of the virus, researchers start to explore the ways of transmission. It is worth mentioning that most of the researchers were agreed on the keeping the social distance and avoiding close contact with sick patients, using hand sensitizer and regular hand washing with face mask and wearing gloves, as well as indirect contact also should be considered, the contaminated surfaces should be disinfected because researcher also agreed that it can be another source of the 2019-nCoV transmission.[15] Researchers were reportedly stated that elderly people and comorbid people had to be more concerns than others in order to be safe from getting infected by the new coronavirus 2019. However most people have concern about recovered COVID-19 patient can infected again by the 2019-nCoV, but researchers pointed to the RNA from SARS-CoV-2 could be the source of infection and recur the COVID-19. The considerable efforts by researcher and racing the related drugs companies and governmental authorities to tackle the situation by finding the miracle drug for COVID-19, but still all the efforts not made changes a word in the statement "currently no drug available for COVID-19 and neither vaccine". The urgent steps need to stop the deadly 2019-nCoV, because it is spread very fast, NIH recommendation rating currently recommended to use up to date. USFDA also recommend convalescent plasma from recovered patients to use for COVID-19 patients.

\section{CONCLUSION}

The review of several researches about the SARS-CoV-2 since its appearance to present time May 2020, and several reports from WHO, CDC and FDA about spreading or the way of transmission, causes, prevention, diagnosis of the novel coronavirus were analyzed. Finally close surveillance or follow up should be considered for recovered patients in order to reducing the risk of recurrence the COVID-19 and pacer patients should be protected further to help in reduction the chance of infection with 2019-nCoV. As the so called novel coronavirus spread very fast and the source of transmission remains unclear. By considering the current review, It can be recommend the governmental health authorities in the territories have to take responsibilities announce some advices to encourage people to follow health authorities regulations and self-protection with protect social distancing to reduce further transmission of the virus, such as reducing close contact with infected people with the virus, regular and frequent hand washing by using liquid soap especially after contact with sick people and contaminated surfaces. Quarantines people with the symptom of coughs and sneezes as well as frequent use of tissues while coughing and sneezing. It is also recommended to not rash to ending the protection regulations and quarantines because the risk of the virus still realistic. Clearly advertising information about the virus itself and well clarification of the COVID-19 could be the priority for the governmental authorities to reduce the risk of the nightmare the so called SARS-CoV-2.

\section{REFERENCE}

[1] T. Zhang, Q. Wu, and Z. Zhang, "Probable Pangolin Origin of SARS-CoV-2 Associated with the COVID-19 Outbreak," Current Biology, vol. 30, pp. 1346-1351.e2, 2020/04/06/ 2020.

[2] S. Ali, T. Hama-Soor, M. Babakir-Mina, S. Dimonte, and F. Greco, "Is It Scaly Anteater or Bat A Real Origin of The 2019-Novel CoV: A Probable Hypothesis? ," Kurdistan Journal of Applied Research, vol. 5, pp. 1-12, 2020

[3] WHO, "Coronavirus Diseases 2019 (COVID-19)- Situation Report-22," WHO11 - February 2020.

[4] WHO, "Coronavirus diseases 2019 (COVID-19)- Situation Report-52," Report12-March 2020.

[5] CDC. (2020). Human Coronavirus. Available: https://www.cdc.gov/coronavirus/types.html

[6] T. Chen, D. Wu, H. Chen, W. Yan, D. Yang, G. Chen, X. Luo, J. Zhao, and Q. Ning, "Clinical characteristics of 
113 deceased patients with coronavirus disease 2019: retrospective study," BMJ, vol. 368, p. m1091, 2020.

[7] T. Zhen-Dong, T. An, L. Ke-Feng, L. Peng, W. Hong-Ling, Y. Jing-Ping, Z. Yong-Li, and Y. Jian-Bo, "Potential Presymptomatic Transmission of SARS-CoV-2, Zhejiang Province, China, 2020," Emerging Infectious Disease journal, vol. 26, 2020.

[8] C. P. Davis. (2020, 30 April). COVID-19 (Coronavirus, 2019-nCoV). Available: https://www.medicinenet.com/wuhan_coronavirus_2019-ncov/article.htm

[9] Q. Li, X. Guan, P. Wu, X. Wang, L. Zhou, Y. Tong, R. Ren, K. S. M. Leung, E. H. Y. Lau, J. Y. Wong, X Xing, N. Xiang, Y. Wu, B. J. Cowling, B. Yang, G. M. Leung, and Z. Feng, "Early Transmission Dynamics in Wuhan, China, of Novel Coronavirus-Infected Pneumonia," New England Journal of Medicine, vol. 382, pp. 1199-1207, 2020 .

[10] C. Jing, S. Wenjie, H. Jianping, G. Michelle, W. Jing, and H. Guiqing, "Indirect Virus Transmission in Cluster of COVID-19 Cases, Wenzhou, China, 2020," Emerging Infectious Disease journal, vol. 26, 2020.

[11] M. krg, "Coronavirus 2019- Situation Update," Ministry of Health, https://gov.krd/coronavirus-en/situationupdate/29 April 2020

[12] D. Zhanwei, W. Lin, C. Simon, X. Xiaoke, W. Xianwen, J. C. Benjamin, and M. Lauren Ancel, "Risk for Transportation of 2019 Novel Coronavirus Disease from Wuhan to Other Cities in China," Emerging Infectious Disease journal, vol. 26, 2020.

[13] G. Kampf, D. Todt, S. Pfaender, and E. Steinmann, "Persistence of coronaviruses on inanimate surfaces and their inactivation with biocidal agents," Journal of Hospital Infection, vol. 104, pp. 246-251, 2020.

[14] N. van Doremalen, T. Bushmaker, D. Morris, M. Holbrook, A. Gamble, B. Williamson, A. Tamin, J. Harcourt, N. Thornburg, S. Gerber, J. Lloyd-Smith, E. de Wit, and V. Munster, "Aerosol and surface stability of HCoV19 (SARS-CoV-2) compared to SARS-CoV-1," medRxiv, p. 2020.03.09.20033217, 2020.

[15] Y. Liu, Z. Ning, Y. Chen, M. Guo, Y. Liu, N. K. Gali, L. Sun, Y. Duan, J. Cai, D. Westerdahl, X. Liu, K. -f. Ho, H. Kan, Q. Fu, and K. Lan, "Aerodynamic Characteristics and RNA Concentration of SARS-CoV-2 Aerosol in Wuhan Hospitals during COVID-19 Outbreak," bioRxiv, p. 2020.03.08.982637, 2020.

[16] CDC, "Coronavirus Disease 2019 (COVID-19)," U.S. Centers for Disease Control and Prevention, https://www.cdc.gov/coronavirus/2019-ncov/symptoms-testing/symptoms.html17-April 2020

[17] B. Udugama, P. Kadhiresan, H. N. Kozlowski, A. Malekjahani, M. Osborne, V. Y. C. Li, H. Chen, S. Mubareka, J. B. Gubbay, and W. C. W. Chan, "Diagnosing COVID-19: The Disease and Tools for Detection," ACS nano, vol. 14, pp. 3822-3835, 2020

[18] NCIRD, "Division of Viral Diseases," National Center for Immunization and Respiratory Diseases27 April 2020.

[19] BD. (2020, 03 April 2020). COVID-19 IgM/IgG Rapid test. Available: https://www.biomedomics.com/products/infectious-disease/covid-19-rt/

[20] T. Ai, Z. Yang, H. Hou, C. Zhan, C. Chen, W. Lv, Q. Tao, Z. Sun, and L. Xia, "Correlation of Chest CT and RT-PCR Testing in Coronavirus Disease 2019 (COVID-19) in China: A Report of 1014 Cases," Radiology, vol. 0, p. 200642.

[21] R. Patanavanich and S. A. Glantz, "Smoking is Associated with COVID-19 Progression: A Meta-Analysis," medRxiv, p. 2020.04.13.20063669, 2020.

[22] J. Lighter, M. Phillips, S. Hochman, S. Sterling, D. Johnson, F. Francois, and A. Stachel, "Obesity in patients younger than 60 years is a risk factor for Covid-19 hospital admission," Clinical infectious diseases : an official publication of the Infectious Diseases Society of America, p. ciaa415, 2020.

[23] W. Liang, W. Guan, R. Chen, W. Wang, J. Li, K. Xu, C. Li, Q. Ai, W. Lu, H. Liang, S. Li, and J. He, "Cancer patients in SARS-CoV-2 infection: a nationwide analysis in China," The Lancet. Oncology, vol. 21, pp. 335$337,2020$.

[24] WHO, "Coronavirus Disease 2019 (COVID-19)," World Health Organisation https://www.who.int/newsroom/q-a-detail/q-a-coronaviruses29 April 2020

[25] B. N. Williamson, F. Feldmann, B. Schwarz, K. Meade-White, D. P. Porter, J. Schulz, N. v. Doremalen, I. Leighton, C. K. Yinda, L. Pérez-Pérez, A. Okumura, J. Lovaglio, P. W. Hanley, G. Saturday, C. M. Bosio, S. Anzick, K. Barbian, T. Cihlar, C. Martens, D. P. Scott, V. J. Munster, and E. d. Wit, "Clinical benefit of remdesivir in rhesus macaques infected with SARS-CoV-2," bioRxiv, p. 2020.04.15.043166, 2020.

[26] P. Gautret, J.-C. Lagier, P. Parola, V. T. Hoang, L. Meddeb, M. Mailhe, B. Doudier, J. Courjon, V. Giordanengo, V. E. Vieira, H. T. Dupont, S. Honoré, P. Colson, E. Chabrière, B. La Scola, J.-M. Rolain, P. Brouqui, and D. Raoult, "Hydroxychloroquine and azithromycin as a treatment of COVID-19: results of an open-label non-randomized clinical trial," International Journal of Antimicrobial Agents, p. 105949, 2020/03/20/2020

[27] NIH, "Coronavirus Disease (COVID-19) treatment guidline " National Institute of Health, https://covid19treatmentguidelines.nih.gov/29 April 2020.

[28] E. Mahase, "Covid-19: What do we know so far about a vaccine?," BMJ, vol. 369, p. m1679, 2020.

[29] K. Duan, B. Liu, C. Li, H. Zhang, T. Yu, J. Qu, M. Zhou, L. Chen, S. Meng, Y. Hu, C. Peng, M. Yuan, J. Huang, Z. Wang, J. Yu, X. Gao, D. Yu, J. Hou, Z. Shi, S. Chen, Z. Chen, X.-X. Zhang, and X. Yang, "The feasibility of convalescent plasma therapy in severe COVID-19 patients: a pilot study," medRxiv, p. 2020.03.16.20036145, 2020.

[30] D. Chen, W. Xu, Z. Lei, Z. Huang, J. Liu, Z. Gao, and L. Peng, "Recurrence of positive SARS-CoV-2 RNA in COVID-19: A case report," International Journal of Infectious Diseases, vol. 93, pp. 297-299, 2020/04/01/ 2020 